\title{
The Scotopic Threshold Response in Diabetic Retinopathy
}

\author{
G. W. AYLWARD \\ Sydney, Australia
}

\begin{abstract}
Summary
The scotopic threshold response (STR) is a recently discovered component of the electroretinogram. It is a corneal negative deflection elicited in the fully dark adapted eye to dim stimuli, and appears to originate in the inner retina. The STR was recorded in a group of 50 insulin dependent diabetics with various degrees of diabetic retinopathy, who had not undergone laser photocoagulation. In addition, the scotopic b-wave, oscillatory potentials (OPs) and a pattern electroretinogram (PERG) were recorded. Retinopathy was assessed with stereo colour photographs of the seven standard fields as defined in the Diabetic Retinopathy Study. Retinopathy level was assigned to each eye using a modification of the Airlie House Classification System. Fluorescein angiograms were taken using $a 0^{\circ}$ fundus camera and graded for the presence of leakage and capillary non-perfusion. There was a significant correlation between the severity of retinopathy and the amplitude and latency of the STR. There was a similar correlation with the amplitude and latency of the OPs, a weaker correlation with the amplitude of the PERG, but no significant correlation with the latency of the PERG. These results support an inner retinal origin for the STR and suggest a role for STR in the electroretinographic assessment of diabetic retinopathy.
\end{abstract}

The a-wave and the b-wave of the electroretinogram are normal in eyes with diabetic retinopathy, unless the disease is very advanced. ${ }^{1}$ Abnormalities of oscillatory potentials (OPs) occur with lesser degrees of retinopathy ${ }^{2}$ and seem to have some clinical value in predicting progression. ${ }^{3,4}$ The pattern electroretinogram (PERG) is also abnormal in diabetic retinopathy ${ }^{5}$ but may be affected at a later stage of the disease than OPs. ${ }^{6}$ OPs are thought to be generated in the inner retina ${ }^{7}$ and there is good evidence that the PERG also originates from the inner retina, probably from ganglion cells. ${ }^{8}$ It is probable that abnormalities in OPs and the PERG reflect disturbances of the retinal circulation that occur in diabetic retinopathy. The scotopic threshold response (STR) is a corneal negative deflection which has recently been described in the cat. It is elicited in the fully dark-adapted eye to the very dim stimuli, and appears to arise in proximal retina. ${ }^{9}$ It may be recorded in man using conventional equipment with minor modification. ${ }^{10,11}$ The present study was conducted to discover the answer to two questions. First, do abnormalities of the STR occur in diabetic retinopathy? Secondly, which components of 
the ERG correlate best with severity of retinopathy.

\section{Patients and Methods}

Diabetic subjects were sought who met the following criteria.

(1) Age between 15 and 55 years with insulin dependent diabetes mellitus for more than 10 years

(2) Any grade of retinopathy

(3) No ocular or systemic disease other than diabetes

(4) Clear media.

Patients who had received photocoagulation to both eyes were excluded, to avoid possible effects of photocoagulation on the ERG. Fifty patients were recruited into the study, 22 males and 28 females with a mean age of 37 years (range 15 to 55 years). The mean duration of diabetes was 17 years (range 10 to 42 years), and the mean age at diagnosis was 19 years (range 1 to 43 years). Forty-five subjects $(90 \%)$ had been diagnosed diabetic at the age of 35 or less. In addition, 10 normal subjects who were age matched to a group of diabetics without retinopathy, were examined. The normal subjects underwent the same examination as the diabetics with the exception of colour and fluorescein photography.

Each patient received a full history and ophthalmological examination followed by electroretinography, colour photography and fluorescein angiography as described below. One eye of each subject was designated the study eye. The choice was made according to the toss of a coin unless one eye had received laser photocoagulation, in which case the untreated eye was chosen.

All ERGs were recorded from both eyes simultaneously using gold foil electrodes manufactured in our laboratory from gold plated plastic film. ${ }^{12}$ Reference electrodes were silver/silver chloride (3M red dot) electrodes which were placed on the ipsilateral temple, and another on the forehead acted as the earth. Signals were amplified and filtered before being fed to a PDP11/23 computer via an analogue to digital converter. Software incorporating automatic artifact rejection was used to average and store the signals for later analysis.
The stimulus for the PERG was a reversing checkerboard pattern produced on a high resolution monitor using an electronic grating generator. The reversal frequency was $2 \mathrm{~Hz}$ and the check size was $1 \mathrm{~cm}$ a side. The luminance of the pattern was $120 \mathrm{cdm}^{-2}$ for the white squares, and $15 \mathrm{cdm}^{-2}$ for the black squares, giving a contrast of $78 \%$. The subject was seated facing the monitor at a distance of $28 \mathrm{~cm}$ measured from the cornea. At this distance the angular dimensions of the pattern were $68^{\circ} \times 58^{\circ}$, and the side of one check subtended 2 degrees. The PERG was recorded under full room illumination and with natural pupils. Signals were amplified 50,000 times and filtered between 0.5 and $300 \mathrm{~Hz}$. A recording epoch of $200 \mathrm{~ms}$ was used and 256 artifact-free signals were averaged and stored.

On completion of the PERG, the gold foil electrodes were removed and both pupils were dilated with topical cyclopentolate $1 \%$ and phenylephrine $10 \%$. The subject was dark adapted for 30 minutes. The gold foil electrodes were then reinserted under dim red illumination and all remaining ERGs were recorded over a period of about 15 minutes. The pupil diameter was measured at the end of the recording session using a transparent millimetre rule.

The stimulus for the remaining ERGs was a Ganzfeld bowl of $40 \mathrm{~cm}$ diameter, fitted with a Grass PS22 photic stimulator, which was used on its highest intensity setting. A dual filter wheel was mounted between the flash and the bowl with suitable screening to prevent light leakage. The filter wheels contained combinations of neutral density filters allowing attenuation of the flash of up to $9.3 \mathrm{log}$ units in 0.3 logunit steps. A blue filter (peak $450 \mathrm{~nm}$ ) was also placed in the light path. The apparatus was calibrated using a phototransistor which responded to brief flashes, itself calibrated with a digital photometer. Photometric measurements were converted to scotopic trolands using the pupil diameter for each eye and standard conversion factors. ${ }^{13}$

Recordings were made to stimuli over a range of intensity beginning below psychophysical threshold and increasing in $0.3 \mathrm{log}$ unit steps to the highest intensity available. The recording conditions varied according to 
Table I Recording conditions used for the STR, $b$-wave and OPs

\begin{tabular}{lcccccc}
\hline & $\begin{array}{c}\text { Flash } \\
\text { rate } \\
(\mathrm{Hz})\end{array}$ & $\begin{array}{c}\text { Range of } \\
\text { attenuation } \\
\text { (logunits) }\end{array}$ & $\begin{array}{c}\text { Amplifier } \\
\text { gain }\end{array}$ & $\begin{array}{c}\text { Filter } \\
\text { range } \\
(\mathrm{Hz})\end{array}$ & $\begin{array}{c}\text { Recording } \\
\text { epoch } \\
(\mathrm{ms})\end{array}$ & $\begin{array}{c}\text { Signals } \\
\text { averaged }\end{array}$ \\
\hline STR & 1 & $\begin{array}{c}6.9-4.5 \\
\text { (approx) }\end{array}$ & 100,000 & $0.5-300$ & 300 & 32 \\
b-wave & 1 & $\begin{array}{c}4.2-1.2 \\
\text { (approx) }\end{array}$ & 10,000 & $0.5-300$ & 300 & 16 \\
OPs & 0.5 & \begin{tabular}{c}
$1.2-0.0$ \\
\hline
\end{tabular} & 100,000 & $100-300$ & 200 & 8 \\
\hline
\end{tabular}

the nature of the response and are shown in Table I.

A typical PERG is shown in Figure 1. The waveform consists of a small negative deflection (N1) following by a positive deflection (P1) and then a larger negative deflection (N2). The amplitude of P1 was measured from the trough of $\mathrm{N} 1$ to the peak of P1. The amplitude of $\mathrm{N} 2$ was measured from the peak of P1 to the trough of $\mathrm{N} 2$. Implicit times were measured from the time of pattern reversal to the peak of P1 and N2.

Figure 2 shows a typical intensity response series showing the STR and scotopic b-wave. The STR was analysed in the following way. The amplitude and latency were defined (Fig. 3). Linear regression analysis was used to find the best fit of amplitude to log retinal illuminance. The amplitude at a point 0.3 logunits below b-wave threshold was determined from the regression line, and this value, which will be referred to as Smax, was used for further analysis. This level of illuminance was chosen as it was generally that at which the STR was largest, since destructive interference from the $b$-wave reduced the size of the signal at the next highest illuminance (Fig. 4a). An arbitrary criterion threshold of $5 \mathrm{uV}$ was chosen and the illuminance required to generate an STR of $5 \mathrm{uV}$ was determined from the regression line. This parameter, which will be referred to as CR5, may be considered a measure of retinal sensitivity in the same way as the parameter $\mathrm{K}$ in the Naka-Rushton equation (see below).

A similar process was used to analyse STR latency. Latency data was fit to log retinal illuminance using linear regression analysis. The latency at a point 0.3 logunits below b-wave threshold was determined from the regression line and called SLmin. A criterion threshold of $130 \mathrm{~ms}$ was arbitrarily chosen and used to determine the sensitivity parameter CR130 from the regression line (Fig. 4b).

The amplitude of the b-wave was measured from the trough of the a-wave to the peak of the $b$-wave and plotted against log retinal illuminance. The maximum rod amplitude was chosen by inspection and the parameters of the best fit Naka-Rushton equation ${ }^{14}$ was then found using regression analysis on transformed data. ${ }^{15}$ The three parameters of the Naka-Rushton function are:

(1) Vmax, the maximum amplitude

(2) $\mathrm{K}$, the intensity required for half maximum amplitude

(3) n, a parameter associated with the slope of the curve.

B-wave implicit time was analysed by finding VIDE-ANGLE PERG

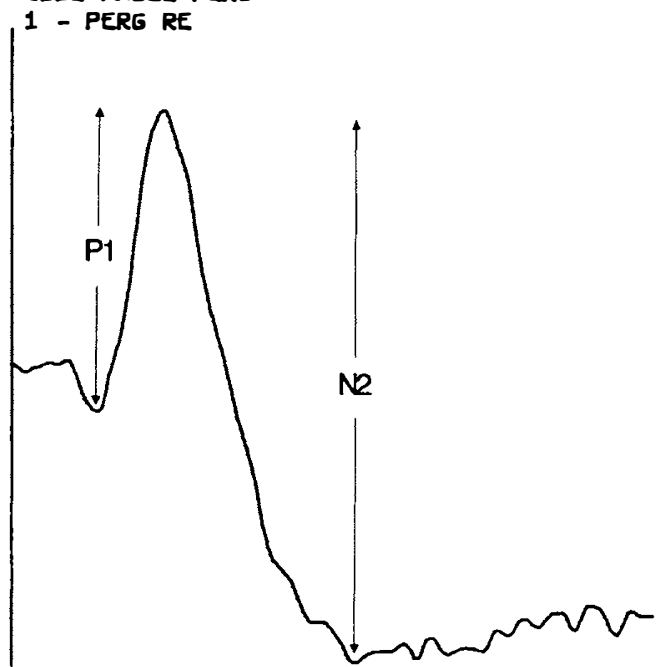

$X$-AXIS $=204.7 \mathrm{mS}, Y$-AXIS $-25.00 \mathrm{uV}$

Fig. 1. A typical PERG showing the method of measuring the amplitude of P1 and N2. 
10uv

$50 \mathrm{rrs}$

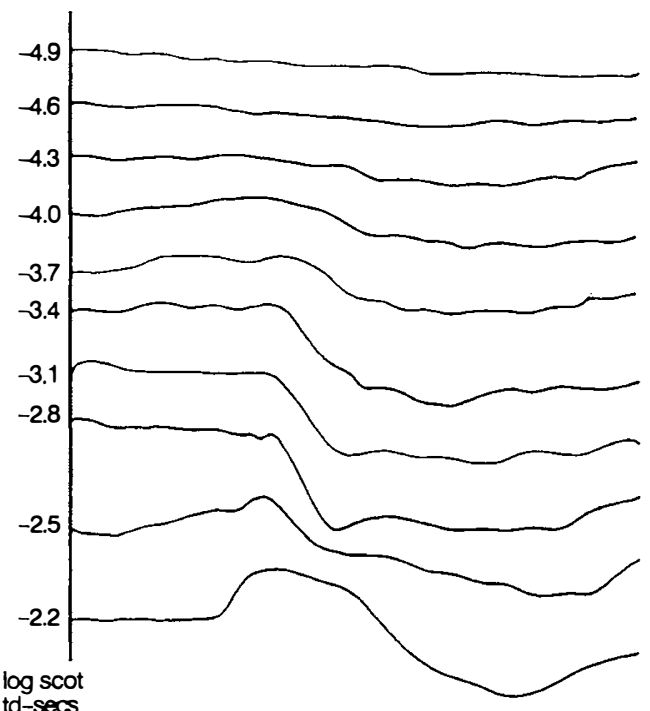

100uv

$50 \mathrm{~ms}$

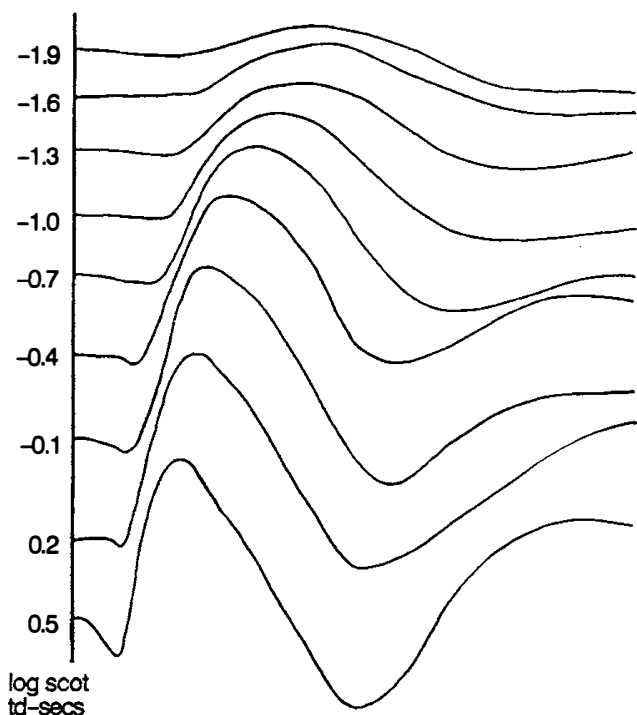

Fig. 2. A typical intensity-response series. Retinal illuminance increases from the top left to the bottom right. Note the difference in scale between the left and the right column. Psychophysical threshold was -5.1 log scotopic troland seconds for this subject. The STR can be clearly seen as a negative deflection which increases in size over a small range of retinal illuminance from about 1.5 logunits above psychophysical threshold up to b-wave threshold.

the best fit to log retinal illuminance using linear regression. The implicit time at a retinal illuminance of $\mathrm{K}$ was then read from the curve and used for subsequent analysis. A-wave implicit time was also fitted to log retinal illuminance using linear regression analysis. Two further sensitivity parameters were defined using criterion thresholds of $100 \mathrm{~ms}$ for the b-wave (CR100) and $50 \mathrm{~ms}$ for the a-wave (CR50).

The use of a high pass analogue filter when recording OPs eliminates the low frequency components that constitute the a-wave and b-wave. This results in a signal of the form shown in Figure 5. In all cases four wavelets could be identified, and are referred to as OP1, OP2, OP3 and OP4. Each OP was analysed separately in the following way. The amplitude was measured from the preceding trough to the peak of the OP. The amplitude varied as a function of retinal illuminance and generally peaked in the middle of the range of illuminance, but the position of the peak varied between the OPs in an inconsistent manner. A typical example is shown in Figure 6. Therefore the average amplitude for the five retinal illuminances at which OPs were recorded was used in further analysis. The implicit time of each OP was fit to log retinal illuminance using linear regression. The implicit time at a retinal illuminance of $1.5 \mathrm{log}$

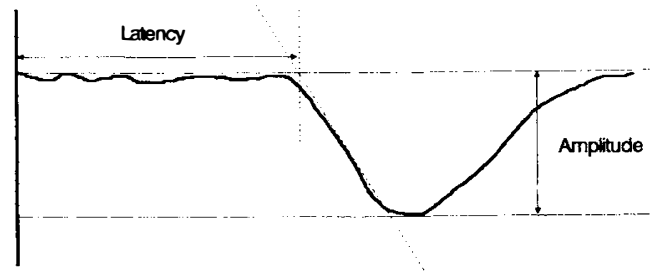

Fig. 3. The amplitude of the STR was measured from the baseline to the peak of the negative deflection. The latency was measured from stimulus onset to the point of intersection of the baseline with a line drawn tangentially to the steepest downgoing portion of the negative deflection. 


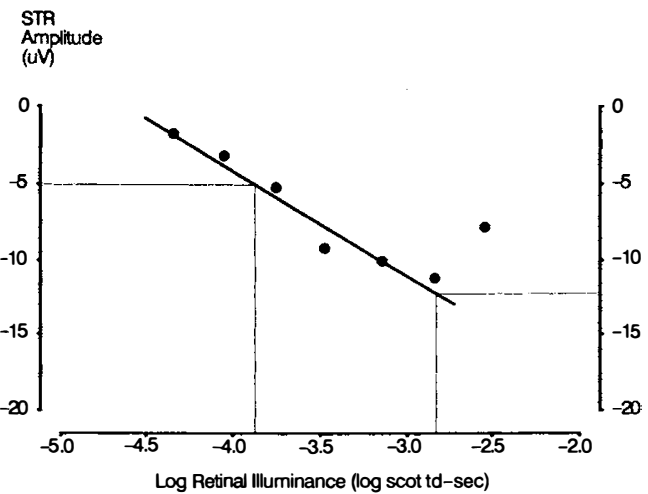

Fig. 4a. The amplitude of the STR plotted against log retinal illuminance with the regression line shown. The point at about $-2.5 \mathrm{log}$ scot $t$ secs was reduced due to destructive interference from the $b$-wave, and was therefore not included in the regression. Smax was read from the regression line at the level of illuminance 0.3 logunits below $b$-wave threshold. The value of illuminance for a criterion threshold of $5 \mathrm{uV}(\mathrm{CR} 5)$ was also read from the regression line.

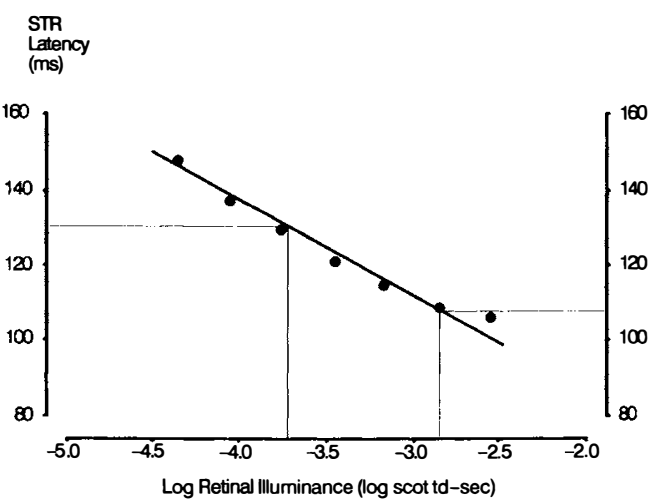

Fig. 4b. The latency of the STR plotted against log retinal illuminance with the regression line shown. The latency at the same level of illuminance at which Smax was read (SL min) was determined from the regression line. The value of illuminance for a criterion threshold of $130 \mathrm{~ms}$ (CR130) was also read from the regression line.

scot td-secs was determined from the graph and this value was then used for subsequent analysis.

Diabetic retinopathy was assessed photographically. Colour stereo photographic pairs of the seven standard fields as defined in the diabetic retinopathy study ${ }^{16}$ were taken using a Zeiss F3 fundus camera. The photographs were graded by comparison with standard photographs according to an adaption of the
Airlie House classification scheme. ${ }^{17}$ An overall grade was assigned to each eye based on the greatest degree of retinopathy in any field. Wide angle fundus fluorescein angiograms were taken with a Canon CF $60 \mathrm{Z} 60^{\circ}$ fundus camera. A capillary phase photograph was taken of the posterior pole followed by at least eight barely overlapping photographs of the peripheral retina. Each frame of the angiogram was graded for fluorescein leakage by comparison with our own standard photographs, on a scale of 0 (absent) to 4 (severe). An overall grade of leakage was assigned to the eye based on the highest grade in any field. An estimate of the proportion of capillary non-perfusion in each frame was made by eye with the assistance of an overlaid grid. An overall grade of capillary non-perfusion from grade 0 (absent) to grade 4 ( $30 \%$ or more) was assigned to the eye according to the average proportion in each frame.

\section{Results}

All but one of the patients had corrected

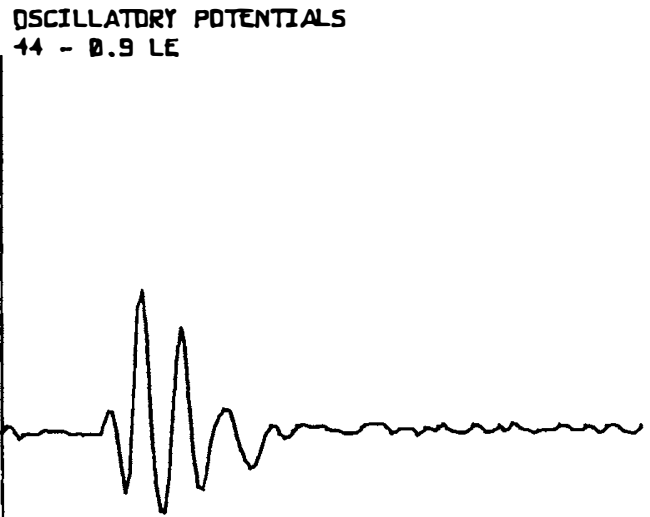

$X$-AXIS $=119.9 \mathrm{mS}, Y$-AXIS $=200.00 \mathrm{uV}$

Fig. 5. A typical set of OPs recorded at a retinal illuminance of $1.1 \mathrm{log}$ scot td secs. The tracing is the average of 8 signals amplified 100,000 times and filtered between $100 \mathrm{~Hz}$ and $300 \mathrm{~Hz}$. The first positive peak was taken as OP1, and the next three peaks OP2, OP3 and OP4 respectively. 


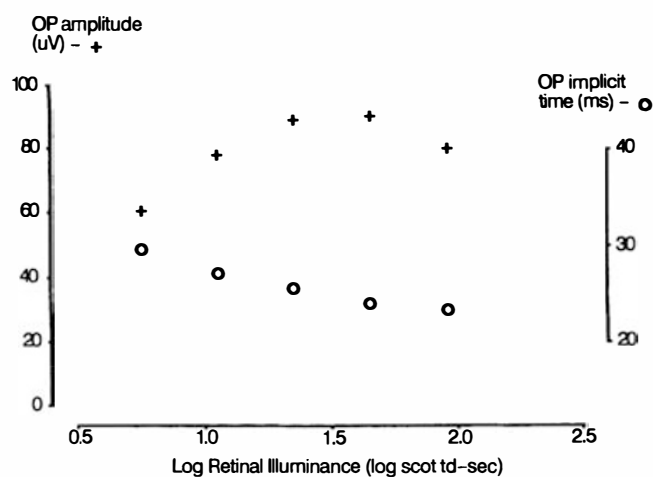

Fig. 6. Amplitude (crosses) and latency (circles) of $O P 2$ plotted against log retinal illuminance. The amplitude of all the OPs generally peaked in the middle of the range of illuminance, and the average of all 5 values was taken as the amplitude to be used in the statistical analysis. The implicit time decreased linearly with log retinal illuminance and linear regression analysis was carried out. The value of implicit time at $1.5 \mathrm{log}$ scot td secs was read from the regression line.

visual acuities of $6 / 6$ or better in the study eye and were asymptomatic at the time of the examination. One patient had a history of vitreous haemorrhage and had received panretinal laser photocoagulation in one eye. The corrected visual acuity in the study eye was $6 / 12$, there were new vessels on the optic disc, and evidence of recent vitreous haemorrhage. Two other patients with optic disc neovascularisation were unaware of its presence.

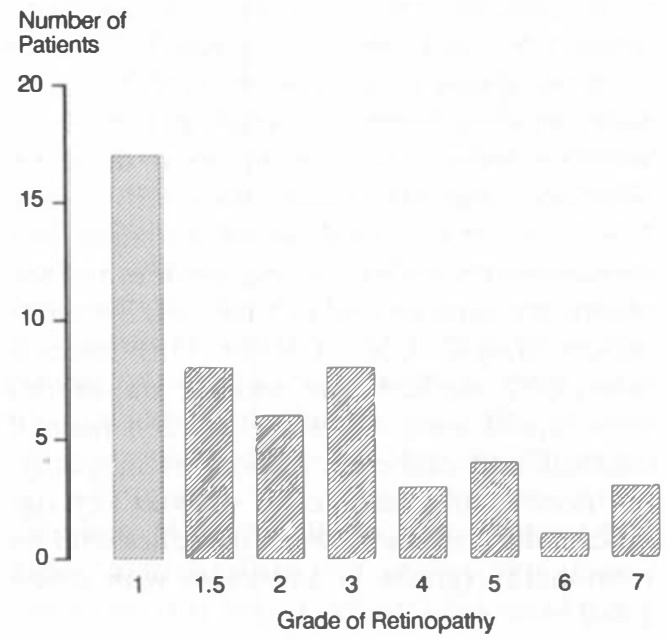

(a)
The distribution of the grade of retinopathy as determined by stereo colour photography is shown in Figure 7a. The distribution of the grade of fluorescein leakage and capillary non-perfusion is shown in Figure $7 \mathrm{~b}$.

The relationship between the severity of retinopathy and each of the electrophysiological parameters defined above, was examined by determining the coefficients of simple correlation, which are shown in Table II. There were significant correlations between the grade of retinopathy and the following parameters; the amplitude of P1 and N2, the amplitude of the STR and all the OPs, including the summed amplitude, the latency of the STR and the implicit times of OP1 and OP2, but not OP3 or OP4. There was no significant correlation between the grade of retinopathy and any of the parameters derived from the b-wave. A similar set of correlations was found for fluorescein leakage and capillary non-perfusion. Figure 8 displays the data for several of the parameters in scatterplots to show the relationship with grade of retinopathy in more detail.

The relationship between the various parameters and the three measures of retinopathy was further investigated using stepwise multivariate regression analysis. The analysis included age, duration of diabetes and sex, which was coded as an indicator variable

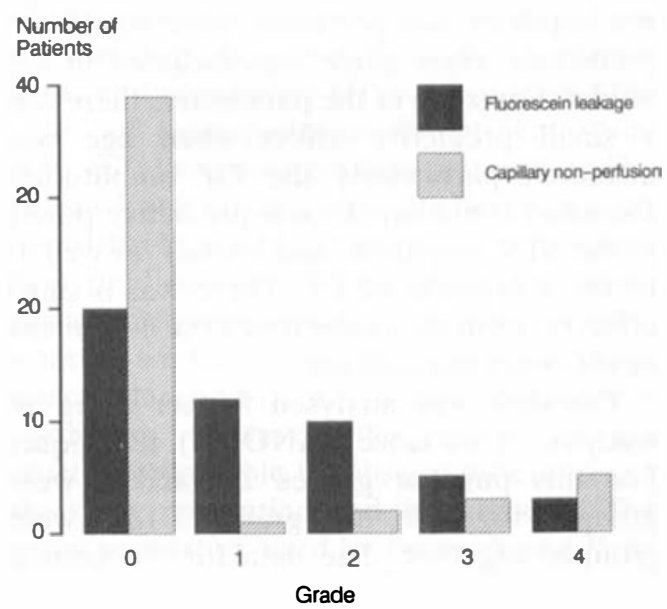

(b)

Fig. 7. Histogram showing distribution of (a) grade of retinopathy and (b) fluorescein leakage and capillary nonperfusion, among the diabetic subjects. 
Table II Coefficients of simple correlation of the electrophysiological parameters against measures of retinopathy

\begin{tabular}{lccc}
\hline Parameter & $\begin{array}{c}\text { Grade of } \\
\text { retinopathy }\end{array}$ & $\begin{array}{c}\text { Fluorescein } \\
\text { leakage }\end{array}$ & $\begin{array}{c}\text { Capillary } \\
\text { non-perfusion }\end{array}$ \\
\hline P1 amplitude & $-0.51^{* *}$ & $-0.36^{* *}$ & $-0.38^{* *}$ \\
P1 implicit time & -0.14 & -0.12 & -0.04 \\
N2 amplitude & $0.42^{* *}$ & $0.31^{*}$ & $0.29^{*}$ \\
N2 implicit time & 0.05 & 0.08 & 0.07 \\
Smax & $0.63^{* *}$ & $0.61^{* *}$ & $0.55^{* *}$ \\
CR5 & $0.45^{* *}$ & $0.44^{* *}$ & $0.46^{* *}$ \\
SLmin & $0.64^{* *}$ & $0.62^{* *}$ & $0.59^{* *}$ \\
CR130 & $0.51^{* *}$ & $0.48^{* *}$ & $0.53^{* *}$ \\
Vmax & -0.21 & -0.02 & -0.12 \\
logK & 0.17 & 0.02 & 0.03 \\
n & 0.10 & 0.12 & 0.25 \\
Implicit time @ K & 0.20 & 0.21 & $0.36^{*}$ \\
CR100 & 0.19 & $0.36^{*}$ \\
CR50 & 0.26 & 0.05 & 0.14 \\
OP1 amplitude & 0.11 & $-0.48^{* *}$ & $-0.48^{* *}$ \\
OP1 implicit time & $-0.57^{* *}$ & $0.51^{* *}$ & $0.60^{* *}$ \\
OP2 amplitude & $0.66^{* *}$ & $-0.63^{* *}$ & $-0.60^{* *}$ \\
OP2 implicit time & $-0.69^{* *}$ & $0.35^{*}$ & $0.44^{* *}$ \\
OP3 amplitude & $0.48^{* *}$ & $-0.61^{* *}$ & $-0.64^{* *}$ \\
OP3 implicit time & $-0.71^{* *}$ & 0.16 & 0.15 \\
OP4 amplitude & 0.18 & $-0.52^{* *}$ & $-0.57^{* *}$ \\
OP4 implicit time & $-0.64^{* *}$ & -0.10 & -0.16 \\
Summed OP amplitudes & -0.12 & $-0.62^{* *}$ & $-0.63^{* *}$ \\
\hline
\end{tabular}

* significance level $\mathrm{p}<0.05$.

${ }^{* *}$ significance level $\mathrm{p}<0.01$

$($ male $=1$, female $=2)$. Only parameters which correlated with the severity of retinopathy were analysed. The results are shown in Table III. Grade was a significant predictor for all parameters but neither fluorescein leakage nor capillary non-perfusion were significant predictors when grade was included in the model. For some of the parameters there was a small predictive effect when age was included, particularly the OP amplitudes. Duration contributed some predictive power to the STR amplitude and latency, as well as to the amplitude of $\mathrm{P} 1$. There was a small effect of sex in the model for P1 but not for any of the other parameters.

The data was analysed further using an analysis of variance (ANOVA) technique. For this purpose grades 1.5 and 2 were grouped together, and grades 3 to 7 were grouped together. The data for the normal subjects was also included in the analysis. A normal subject without diabetes was classed as grade 0 retinopathy. The means and standard deviations of all the parameters in the four different groups are shown in Table IV. The results of the analysis of variance for the STR amplitude are shown in Table $\mathrm{V}$ as an example. There was a significant difference in STR amplitude between the diabetics with grade $1.5-2$ and those with grade $3-7$. There were no significant differences in STR amplitude between normal controls and diabetics with no retinopathy, or between diabetics with no retinopathy and those with grade 1.5-2. A similar analysis of variance was carried out for each of the parameters and the results are summarised in Table VI. Six parameters (LogK, CR5, CR130, OP1 implicit time, OP2 implicit time and $\mathrm{N} 2$ amplitude) were significantly different between normal controls and diabetics without retinopathy, but none of the parameters showed any significant differences between diabetics with no retinopathy (grade 1) and those with grade $1.5-2$.

\section{Discussion}

The results of this study demonstrates a rela- 

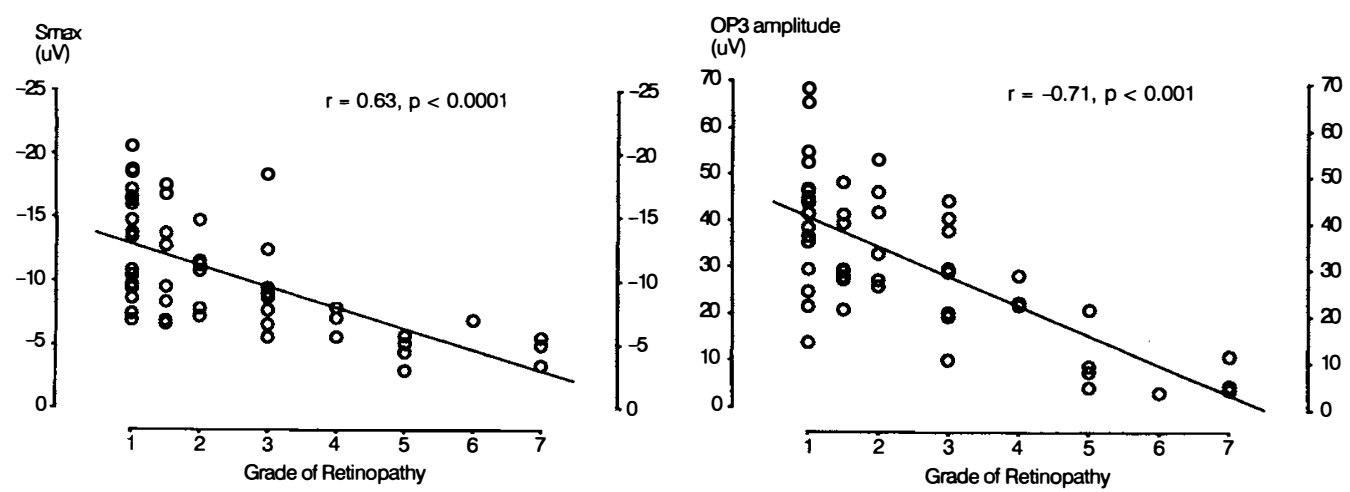

Fig. 8a

Fig. 8b

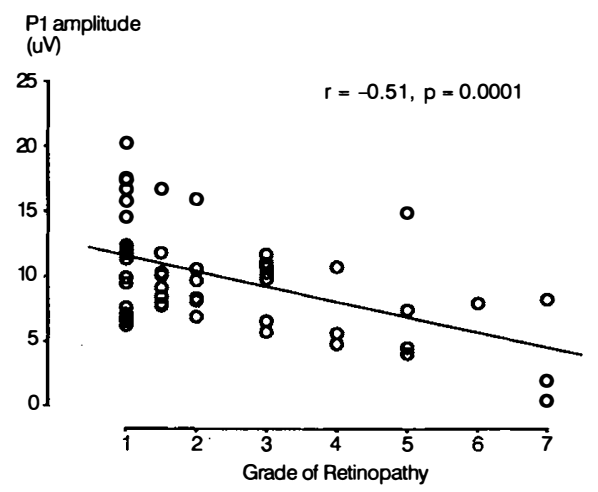

Fig. 8c

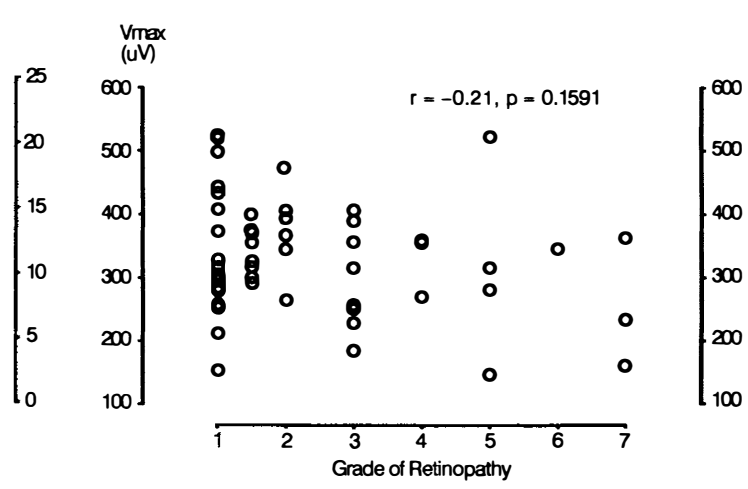

Fig. 8c

Fig. 8. Scattergrams of (a) Smax, (b) amplitude of OP3, (c) amplitude of P1, and (d) Vmax against grade of retinopathy. For the first three of these the fitted regression line and the corresponding correlation coefficient $(r)$ are shown.

tionship between the STR and the severity of diabetic retinopathy. All four parameters derived from the STR (amplitude, latency, CR5 and CR130) correlated with the grade of retinopathy as determined by colour fundus photographs, and with the severity of leakage and capillary non-perfusion on fluorescein angiography. However multivariate regression analysis showed that leakage and capillary non-perfusion were not independent predictors of the STR parameters when grade was included in the model. This is not altogether surprising since the three measures of retinopathy are likely to get worse together. However, it is often the case that widespread capillary non-perfusion is accompanied by very minor ophthalmological signs. There were several cases of this type in the study but probably insufficient to produce a statistically significant effect.
Similar results were obtained for the OPs which confirm previous work ${ }^{18}$ though there were several differences. First, the correlation between the summed OP amplitude and the grade of retinopathy in the present study $(r=-0.71)$ was stronger than that reported by Bresnick $(\mathrm{r}=-0.39)$, secondly Bresnick et al. found that fluorescein leakage was an independent predictor of OP amplitude even when grade was included in the regression model, whereas we have found that neither leakage nor capillary non-perfusion were independent predictors. However, the results are not strictly comparable because of differences in the study population and in technique. The study population used by Bresnick and Palta was older (median age 43.5, range 19-73) and included patients with non-insulin dependent retinopathy. The reduction of OP amplitudes with age, observed in the present study (Table 
Table III Results of multivariate regression analysis for age, sex, duration of diabetes, grade of retinopathy, fluorecein leakage and capillary non-perfusion.

\begin{tabular}{|c|c|c|c|c|}
\hline \multirow{2}{*}{$\begin{array}{l}\text { Dependent } \\
\text { variable }\end{array}$} & \multicolumn{3}{|c|}{$\begin{array}{c}\text { Significant } \\
\text { independent variables }\end{array}$} & \multirow{2}{*}{$\begin{array}{l}\text { Multiple } \\
r\end{array}$} \\
\hline & Variable & Beta & $p$ & \\
\hline P1 amplitude & $\begin{array}{l}\text { grade } \\
\text { duration } \\
\text { sex }\end{array}$ & $\begin{array}{r}-0.439 \\
-0.316 \\
0.298\end{array}$ & $\begin{array}{l}0.00051 \\
0.0069 \\
0.0088\end{array}$ & 0.671 \\
\hline N2 amplitude & $\begin{array}{l}\text { grade } \\
\text { age }\end{array}$ & $\begin{array}{l}0.386 \\
0.451\end{array}$ & $\begin{array}{l}0.0019 \\
0.00053\end{array}$ & 0.617 \\
\hline Smax & $\begin{array}{l}\text { grade } \\
\text { duration }\end{array}$ & $\begin{array}{l}0.589 \\
0.233\end{array}$ & $\begin{array}{l}0.00003 \\
0.037\end{array}$ & 0.675 \\
\hline CR5 & grade & 0.453 & 0.0013 & 0.453 \\
\hline SLmin & $\begin{array}{l}\text { grade } \\
\text { duration }\end{array}$ & $\begin{array}{l}0.592 \\
0.255\end{array}$ & $\begin{array}{l}0.00002 \\
0.021\end{array}$ & 0.689 \\
\hline CR130 & $\begin{array}{l}\text { grade } \\
\text { duration }\end{array}$ & $\begin{array}{l}0.460 \\
0.264\end{array}$ & $\begin{array}{l}0.00072 \\
0.033\end{array}$ & 0.574 \\
\hline OP1 amplitude & $\begin{array}{l}\text { grade } \\
\text { age }\end{array}$ & $\begin{array}{l}-0.551 \\
-0.252\end{array}$ & $\begin{array}{l}0.00008 \\
0.031\end{array}$ & 0.625 \\
\hline OP1 implicit time & grade & 0.661 & 0.00001 & 0.661 \\
\hline OP2 amplitude & grade & -0.691 & 0.00001 & 0.691 \\
\hline OP2 implicit time & grade & 0.476 & 0.00077 & 0.476 \\
\hline OP3 amplitude & $\begin{array}{l}\text { grade } \\
\text { age }\end{array}$ & $\begin{array}{l}-0.693 \\
-0.205\end{array}$ & $\begin{array}{l}0.00001 \\
0.041\end{array}$ & $\begin{array}{l}0.739 \\
0.710\end{array}$ \\
\hline OP4 amplitude & $\begin{array}{l}\text { grade } \\
\text { age }\end{array}$ & $\begin{array}{l}-0.618 \\
-0.226\end{array}$ & $\begin{array}{l}0.00002 \\
0.040\end{array}$ & 0.675 \\
\hline $\begin{array}{l}\text { OPs summed } \\
\text { amplitude }\end{array}$ & $\begin{array}{l}\text { grade } \\
\text { age }\end{array}$ & $\begin{array}{l}-0.696 \\
-0.212\end{array}$ & $\begin{array}{l}0.00001 \\
0.033\end{array}$ & 0.744 \\
\hline
\end{tabular}

III), may have reduced the correlation with grade, particularly if the more severe grades of retinopathy were in the younger, insulin dependent diabetics. Coupland recorded OPs as well as the PERG in a group of diabetic patients and found that OP amplitudes were reduced in diabetics with no retinopathy when compared with normal controls. ${ }^{6}$ The results of the present study do not confirm this although we did find that the implicit times of OP1 and OP2 were significantly higher in diabetics with no retinopathy than in normals. Coupland used a photographic technique to assess retinopathy but only three non-stereo photographs were taken, and the fields were not specified. It is possible that retinas graded as normal on the basis of the three photographs may have had lesions in other frames which would have resulted in a higher grading in the present study.
An interesting finding was the relationship between the implicit times of the OPs and the grade of retinopathy. The implicit times of OP1 and OP2 were highly correlated with grade, but the implicit times of OP3 and OP4 were not. This difference was striking and highly statistically significant (Table II). There is evidence that individual OPs may have separate origins, particularly in respect of the type of photoreceptor involved. ${ }^{19} \mathrm{We}$ used bright blue flashes in the dark adapted eye and it is possible that OP1 and OP2 are cone generated, whereas OP3 and OP4 are rod generated. ${ }^{19}$ However this does not explain why implicit time should have a different relationship to grade of retinopathy than amplitude.

The amplitude of P1 and N2 of the PERG also correlated with severity of retinopathy, although the strength of the correlation was 
Table IV Means and (standard deviations) for the various parameters by grade of retinography

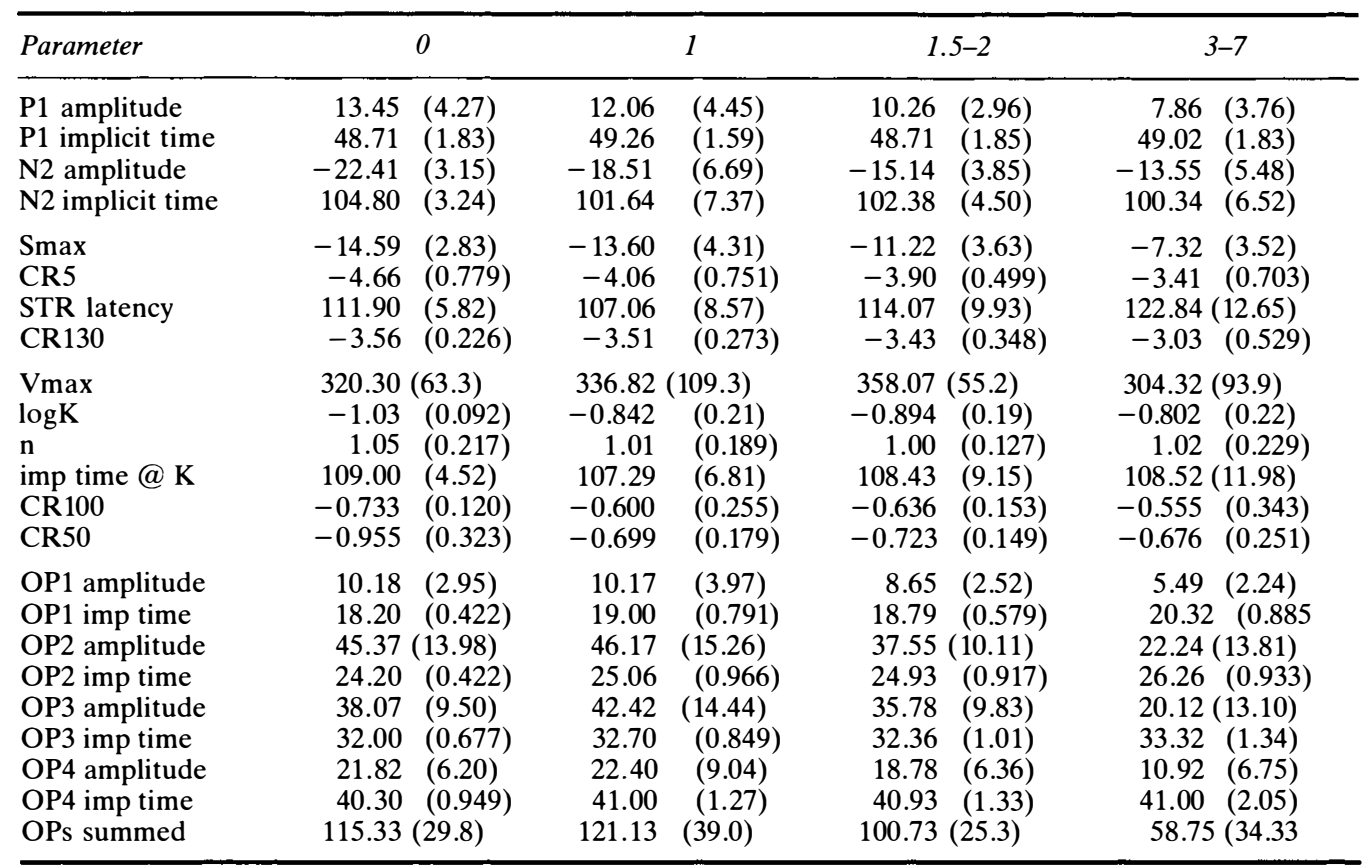

imp = Implicit.

less than the STR and the OPs. Arden et al. found that the PERG was reduced at the preproliferative stage of diabetic retinopathy but could not distinguish between milder forms, ${ }^{5}$ a result confirmed by Coupland. ${ }^{6}$ This may be because the PERG is focal and reflects the integrity of the area of retina on which the pattern falls. We attempted to increase that area by bringing the stimulus closer to the eye, and thereby increase the sensitivity of the PERG to peripheral disease. However, in general our PERG was not sufficiently sensi- tive to distinguish between the paired groups of retinopathy (Table VI), although there was a difference in $\mathrm{N} 2$ amplitude between grade 0 and grade 1 which was significant at the $5 \%$ level. There are many theoretical and practical problems associated with a 'wide-angle' PERG which have been discussed elsewhere. ${ }^{20}$ The contribution of retinal illuminance and pattern specific components in the PERG are dependent on several factors, including spatial frequency, and these vary as the stimulus becomes more periph-

Table V Analysis of variance for STR amplitude

\begin{tabular}{|c|c|c|c|c|c|}
\hline Effect & $S S$ & $d f$ & Ms & $F$ & $p$ \\
\hline $\begin{array}{l}\text { Grade } \\
\text { Within }\end{array}$ & $\begin{array}{l}499.58 \\
764.40\end{array}$ & $\begin{array}{r}3 \\
56\end{array}$ & $\begin{array}{r}166.53 \\
13.65\end{array}$ & 12.20 & 0.00003 \\
\hline \multicolumn{6}{|c|}{ Post hoc comparisons (Fisher's least significant difference method) } \\
\hline Grade & 0 & 1 & $1.5-2$ & $3-7$ & \\
\hline 0 & - & 0.488 & 0.017 & 0.00003 & \\
\hline 1 & 0.488 & - & 0.087 & 0.00013 & \\
\hline $1.5-2$ & 0.017 & 0.087 & - & 0.0069 & \\
\hline $3-7$ & 0.00003 & 0.00013 & 0.0069 & - & \\
\hline
\end{tabular}


Table VI Results of analysis of variance across groups for all electrophysiological parameters

\begin{tabular}{|c|c|c|c|c|c|}
\hline \multirow[b]{2}{*}{ Parameter } & \multirow[b]{2}{*}{$F$} & \multirow[b]{2}{*}{$p$} & \multicolumn{3}{|c|}{ Post-hoc comparison between grade: } \\
\hline & & & 0 and 1 & $\begin{array}{l}1 \text { and } \\
1.5-2\end{array}$ & $\begin{array}{c}1.5-2 \text { and } \\
3-7\end{array}$ \\
\hline P1 amplitude & 5.75 & 0.002 & - & - & - \\
\hline P1 implicit time & 0.336 & 0.801 & - & - & - \\
\hline N2 amplitude & 7.32 & 0.0005 & * & - & - \\
\hline N2 implicit time & 2.18 & 0.099 & - & - & - \\
\hline Smax & 12.19 & 0.00003 & - & - & ** \\
\hline CR5 & 7.49 & 0.00047 & $*$ & - & - \\
\hline SLmin & 7.71 & 0.00039 & - & - & $* *$ \\
\hline CR130 & 6.58 & 0.00097 & - & - & - \\
\hline$V \max$ & 1.10 & 0.355 & - & - & - \\
\hline $\log \mathrm{K}$ & 3.23 & 0.029 & ${ }^{*}$ & - & - \\
\hline $\mathrm{n}$ & 0.122 & 0.943 & - & - & - \\
\hline Implicit time @K & 0.093 & 0.958 & - & - & - \\
\hline CR100 & 1.13 & 0.345 & - & - & - \\
\hline CR50 & 3.72 & 0.016 & $* *$ & - & - \\
\hline OP1 amplitude & 9.15 & 0.00015 & - & - & $* *$ \\
\hline OP1 implicit time & 22.77 & $<0.00001$ & $* *$ & - & $* *$ \\
\hline OP2 amplitude & 11.39 & 0.00004 & - & - & $* *$ \\
\hline OP2 implicit time & 14.09 & 0.00001 & $*$ & - & $* *$ \\
\hline OP3 amplitude & 11.05 & 0.00005 & - & - & $* *$ \\
\hline OP3 implicit time & 4.22 & 0.0094 & - & - & - \\
\hline OP4 amplitude & 8.93 & 0.00017 & - & - & $* *$ \\
\hline OP4 implicit time & 0.547 & 0.655 & - & - & - \\
\hline Summed OP amps & 12.45 & 0.00002 & - & - & $* *$ \\
\hline
\end{tabular}

- no significant difference between groups.

* difference significant $\mathrm{p}<0.05$.

** difference significant $\mathrm{p}<0.01$.

eral. ${ }^{21}$ It is therefore likely that the amplitude of the wide-angle PERG contains contributions from outer retinal components which would reduce its sensitivity to inner retinal disease.

None of the parameters derived from the b-wave correlated with the grade of retinopathy. There was a weak correlation between capillary non-perfusion and both CR100 and the implicit time at $\mathrm{K}$, but this was only significant at the $5 \%$ level (Table II). It is well known that the b-wave may be normal even in advanced retinopathy, and our results confirm this. ${ }^{1}$ However the analysis of variance revealed a difference in $\operatorname{LogK}$ and CR50 between normal subjects and diabetics with no retinopathy. In addition the STR parameter CR5 was also different between these two groups. All three parameters may be considered to be measures of photoreceptor sensitivity, and these results suggest that diabetics have a reduced retinal sensitivity even in the absence of retinopathy. This finding is difficult to explain by pathology in the inner retina alone. Changes in sensitivity have also been reported in retinal vein occlusion ${ }^{22}$ and it is possible that inner retinal disease may compromise outer retinal function due to a shift in oxygen tension. ${ }^{23}$

In conclusion, these results provide clinical evidence to support an inner retinal original for the STR. The STR correlates with the severity of diabetic retinopathy, more strongly than the PERG, but not as strongly as the OPs. OPs also predict progression ${ }^{4}$ but it remains to be seen whether the STR has any predictive value for the progression of diabetic retinopathy. However the STR has some theoretical advantages over the OPs and the PERG for assessment of the inner retina. Firstly it is a pure waveform unlike the OPs which are superimposed on the scotopic b-wave and may be difficult to elicit. ${ }^{7}$ It is a mass response unlike the PERG which is 
focal ${ }^{8}$ and therefore the STR is more likely to reflect disease in the peripheral retina than the PERG.

This study was suported by the Sydney Eye Hospital Foundation (Sylvia Kane Bequest for Research into Diabetic Retinopathy) and by Diabetes Australia (Lions Diabetic Retinopathy Research Grant).

The author wishes to acknowledge the following for their help. Dr Peter Rohl, Dr Paul Mitchell, Professor John Turtle and Dr Philip Clifton-Bligh for allowing access to their clinics; Diabetes Australia for help in recruiting subjects; Mr Brett Jeffrey for computer programming; Dr Catherine Otty for assistance with electroretinography and fluorescein angiography; $\mathrm{Dr}$ Vaegan for helpful discussion and advice; and all study participants for their goodwill and cooperation.

\section{References}

1 Gjotterberg M: The electroretinogram in diabetic retinopathy: A clinical study and critical survey. Acta Ophthalmol 1974, 52: 521-33.

${ }^{2}$ Yonemura D and Kawasaki K: New approaches to ophthalmic electrodiagnosis by retinal oscillatory potentials, drug-induced responses from retinal pigment epithelium and cone potential. Doc Ophthalmol 1979, 48: 163-222.

${ }^{3}$ Simonsen SE: Prognostic value of ERG (oscillatory potential) in juvenile diabetics. Acta Ophthalmol 1975, 123 (suppl): 223-4.

${ }^{4}$ Bresnick GH, Korth K, Groo A, Palta M: Electroretinographic oscillatory potentials predict progression of diabetic retinopathy: preliminary report. Arch Ophthalmol 1984, 102: 1307-11.

${ }^{5}$ Arden GB, Hamilton AMP, Wilson-Holt J, Ryan S, Yudkin JS, Kurtz A: Pattern electroretinograms become abnormal when background diabetic retinopathy deteriorates to a preproliferative stage: possible use as a screening test. $\mathrm{Br} J$ Ophthalmol 1986, 70: 330-5.

${ }^{6}$ Coupland SG: A comparison of oscillatory potential and pattern electroretinogram measures in diabetic retinopathy. Doc Ophthalmol 1987, 66: 20718.

${ }^{7}$ Speros $\mathrm{P}$ and Price J: Oscillatory potentials. History, techniques and potential use in the evaluation of disturbances of retinal circulation. Surv Ophthalmol 1981, 25: 237-51.

${ }^{8}$ Arden GB, Vaegan, Hogg CR: Clinical and experi- mental evidence that the pattern electroretinogram (PERG) is generated in more proximal layers than the focal electroretinogram (FERG). Ann NY Acad Sci 1982, 388: 580-601.

${ }^{9}$ Sieving PA, Frishman LJ, Steinberg RH. Scotopic threshold response of proximal retina in cat. $J$ Neurophysiol 1986, 56: 1048-61.

${ }^{10}$ Sieving PA and Nino C: Scotopic threshold response (STR) of the human electroretinogram. Invest Ophthalmol Vis Sci ARVO Abstracts 1987, 28: 401.

${ }^{11}$ Aylward GW, Vaegan, Billson FA: The scotopic threshold response in man. Clin Vis Sci (in press).

12 Vaegan: An improved method of constructing pattern electroretinogram electrodes. Doc Ophthalmnol Proc Ser 1984, 14: 287-92.

${ }^{13}$ Wyszecki G and Stiles WS: Colour Science. Concepts and methods. Quantitative data and formulas. New York. J. Wiley. 1967.

${ }^{14}$ Naka KI and Rushton WAH: S-potentials from colour units in the retina of fish (Cyprinidae). $J$ Physiol (Lon) 1966, 85: 536-55.

${ }^{15}$ Aylward GW: A simple method of fitting the NakaRushton equation. Clin Vis $\mathrm{Sci}$ (in press).

${ }^{16}$ Diabetic Retinography Study Research Group: Report 7. A modification of the Airlie House classification of diabetic retinopathy. Invest Ophthalmol Vis Sci 1981, 21: 210-26.

${ }^{17}$ Klein R, Klein BEK, Magli YL, Brothers RJ, Meuer SM, Moss SE, Davis MD: An alternative method of grading diabetic retinopathy. Ophthalmology 1986, 93: 1183-7.

${ }^{18}$ Bresnick GH and Palta M: Oscillatory potential amplitudes. Relation to severity of diabetic retinopathy. Arch Ophthalmol 1987, 105: 929-33.

${ }^{19}$ King-Smith PE, Loffing DH, Jones R: Rod and cone ERGs and their oscillatory potentials. Invest Ophthalmol Vis Sci 1985, 27: 270-3.

${ }^{20}$ Aylward GW, Vaegan, Billson FA: The wide-angle pattern electroretinogram. Doc Ophthalmol (in press).

${ }^{21}$ Drasdo N, Thompson DA, Thompson CM, Edwards L: Complementary components and local variations of the pattern electroretinogram. Invest Ophthalmol Vis Sci 1987, 28: 158-62.

22 Johnson MA, Marcus S, Elman MJ, McPhee TJ: Neovascularisation in central retinal vein occlusion: Electroretinographic findings. Arch Ophthalmol 1988, 106: 348-52.

${ }^{23}$ Flower RW and Patz A: The effect of hyperbaric oxygenation on retinal ischaemia. Invest Ophthalmol Vis Sci 1971, 10: 605-16. 